\title{
TOXICIDADE E EFICIÊNCIA DO DIMETILSULFÓXIDO (DMSO) NO CONGELAMENTO DE CÉLULAS MADIN-DARBY BOVINE KIDNEY (MDBK)
}

\author{
PICOLI, Tony ${ }^{1}$; \\ BARBOSA, Jéssica Sevilha ${ }^{2}$; \\ VARGAS, Gilberto D'Ávila ${ }^{3}$; \\ HÜBNER, Silvia de Oliveira ${ }^{3}$; \\ FISCHER, Geferson ${ }^{3}$.
}

Recebido: $11 / 05 / 2015$

Aceito: 07/12/2015

${ }^{1}$ Doutorando do Programa de Pós-Graduação em Veterinária, Universidade Federal de Pelotas; ${ }^{2}$ Acadêmica de Medicina Veterinária, Universidade Federal de Pelotas; ${ }^{3}$ Professor Doutor, Laboratório de Virologia e Imunologia da Faculdade de Veterinária, Universidade Federal de Pelotas.

\section{RESUMO}

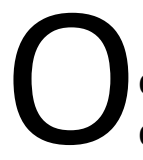

dimetilsulfóxido (DMSO) é um composto mundialmente utilizado como solvente orgânico que nas últimas décadas vem sendo usado na medicina principalmente como anti-inflamatório. Em laboratórios de cultivo celular é utilizado rotineiramente como crioprotetor de células e, sendo assim, objetivou-se estudar a toxicidade e eficiência no congelamento celular, em diferentes concentrações e tempos de exposição. Células da linhagem MDBK (Madin-Darby Bovine Kidney) foram cultivadas em placas de 96 cavidades e, posteriormente, DMSO em concentrações que variaram de $0,5 \%$ a $20 \%$ foi adicionado em períodos que variaram de 15 minutos a 24 horas de exposição. Após, a viabilidade celular foi avaliada pelo ensaio do 3-(4,5 dimetiltiazol-2yl)-2-5-difenil-2H tetrazolato de bromo (MTT). Concomitantemente, células MDBK cultivadas em garrafas foram tripsinizadas e congeladas com diferentes concentrações de DMSO. Após o descongelamento, foi realizada a contagem de células viáveis com azul de tripan. Os resultados obtidos não apresentaram diferença $(p>0,05)$ entre os tratamentos utilizando-se $0,5 \%, 1 \%$ e $2,5 \%$ de DMSO, uma vez que a morte celular não ultrapassou $22,84 \% \pm 3,97 \%$ com 24 horas de incubação. Porém nos tratamentos com maior concentração, com apenas uma hora de incubação, a taxa de morte celular ultrapassou os $20 \%$, diferindo do controle $(p<0,01)$. Após o descongelamento, o melhor protocolo foi aquele que utilizou $10 \%$ de DMSO, não diferindo do controle $(p>0,05)$. As concentrações não tóxicas para células avaliadas pelo ensaio do MTT, não foram capazes de impedir o rompimento celular após congelamento e descongelamento. Conclui-se que é necessário o uso de crioprotetor para o congelamento, porém a adição do DMSO deve ser apenas momentos antes do congelamento devido à sua toxicidade quando incubado com as células. 
Palavras-chave: Criopreservação. Cultivo celular. Citoprotetor.

\section{INTRODUÇÃO}

O dimetilsufóxido (DMSO) é um composto conhecido pela utilização como solvente orgânico desde a segunda metade do século XIX, quando era facilmente obtido como subproduto da indústria de extração de celulose, motivo pelo qual era utilizado em grande escala com fins industriais (BANNISTER et al., 1987). No início do século passado já era utilizado na medicina porém sem comprovações científicas. No entanto, na década de 80 , com a descoberta de suas propriedades anti-inflamatória e citoprotetora, os estudos avançaram e é até hoje uma das substâncias com potencial farmacêutico das mais estudadas (SHIRLEY et al., 1978).

O DMSO, cuja fórmula química é $\left(\mathrm{CH}_{3}\right)_{2} \mathrm{SO}$ (ROSENBAUM et al., 1965) e peso molecular de 78 (CARPENTER et al., 1994), quando exposto ao ambiente, rapidamente passa para concentrações de $66 \%$ ou $67 \%$, devido a sua alta afinidade pelo hidrogênio, motivo pelo qual requer armazenamento em recipiente hermeticamente fechado (ALSUP; DE BOWES, 1984). Nos casos de administração tópica, reage com a água do ar e dos tecidos por meio de reação exotérmica, o que explica algumas de suas funções farmacológicas e seu alto poder de penetrabilidade (BRAYTON, 1986; ROSENBAUM et al., 1965) além da capacidade de interagir com ácidos nucléicos, carboidratos, lipídeos, proteínas e vários fármacos sem alterar, de forma irreversível, a configuração molecular (RUBIN, 1983).

Durante o processo de congelamento de células, os cristais de gelo, formados no meio extracelular, aumentam a concentração de solutos nesse meio, causando uma hiperosmolaridade extracelular, o que leva à desidratação celular. Porém isso apenas ocorre em processos de congelamento excessivamente lentos. A permeabilidade celular à água parece ser o fator limitante para estabelecer o processo de congelamento seguro (MASSUMOTO; MIZUKAMI, 2000). Contudo, em casos de congelamento rápido, a água intracelular não passa para o meio extracelular com a mesma velocidade da queda brusca da temperatura, o equilíbrio osmótico não é mantido, ocorrendo congelamento intracelular (TONER, 1993). 
As técnicas laboratoriais de cultivo celular utilizam o DMSO pela sua função crioprotetora. A adição dessa substância diminui o volume de água para formação de cristais de gelo e, consequentemente, o grau de desidratação celular, já que substitui a água nas células pelo seu poder de penetrabilidade e difusão pela membrana lipídica (DE VRIES et al., 2004). Sendo assim, o presente estudo objetivou avaliar a toxicidade do DMSO em células MadinDarby Bovine Kidney (MDBK) em função do tempo de exposição à diferentes concentrações e a eficiência na recuperação celular após congelamento.

\section{MATERIAL E MÉTODOS}

Para o estudo foram utilizadas células da linhagem MDBK, pertencentes ao Laboratório de Virologia e Imunologia da Faculdade de Veterinária da UFPEL, estocadas em nitrogênio líquido até o momento do uso. Estas células foram cultivadas em Meio Essencial Mínimo (EMEM, Sigma-Aldrich ${ }^{\star}$, USA) suplementado com soro fetal bovino (SFB, Gibco ${ }^{\circ}$ USA), penicilina (Sigma-Aldrich ${ }^{\oplus}$, USA), estreptomicina (Vetec ${ }^{\oplus}$, Brasil), enrofloxacina (Bayer ${ }^{\oplus}$, Brasil) e anfotericina B (Cristália ${ }^{\oplus}$, Brasil) em garrafas adequadas para este fim, fechadas hermeticamente e mantidas à temperatura de $37{ }^{\circ} \mathrm{C}$. No momento do experimento, o cultivo celular sofreu tripsinização e, em placas de 96 cavidades, foram colocados $100 \mu \mathrm{L} /$ poço contendo aproximadamente $3 \times 10^{4}$ células em E-MEM com SFB a $10 \%$. As placas foram incubadas por 24 horas à temperatura de $37{ }^{\circ} \mathrm{C}$ em estufa de $\mathrm{CO}_{2}$ a $5 \%$, após o estabelecimento do tapete celular o sobrenadante foi desprezado e foram realizados os tratamentos.

O DMSO (Synth ${ }^{\oplus}$, pureza 99,9\%) foi diluído em E-MEM até atingir concentrações de 0,5\%, $1 \%, 2,5 \%, 5 \%, 10 \%$ e $20 \%$ e, de cada concentração, $100 \mu \mathrm{L}$ em sextuplicata foram transferidos às cavidades da placa, sobre o tapete celular. Após o tratamento, as células permaneceram incubadas sob as mesmas condições por 15 minutos, 30 minutos, 1 hora, 3 horas, 6 horas, 12 horas e 24 horas. Em seguida, as placas foram retiradas da estufa e foi aplicado o protocolo do reagente MTT para verificação da viabilidade celular (MOSMANN, 1983). Após cuidadosa aspiração do sobrenadante, $50 \mu \mathrm{L}$ da solução $\mathrm{MTT} 1 \mathrm{mg} / \mathrm{mL}$ foi transferida para cada cavidade e as placas foram incubadas nas mesmas condições por 4 horas, quando os sobrenadantes foram retirados e os sais de formazan foram solubilizados. 
As absorbâncias foram obtidas em espectrofotometria sob comprimento de onda de $492 \mathrm{~nm}$ após 15 minutos de leve agitação das placas para estabilização da cor.

Paralelamente, células MDBK em fase exponencial de crescimento foram tripsinizadas, ressuspendidas em E-MEM e transferidas para criotubos de congelamento com $50 \%$ de SFB e concentrações de $0 \%, 0,5 \%, 1 \%, 2,5 \%, 5 \%, 10 \%, 20 \%, 30 \%$ e $40 \%$ de DMSO. As células foram congeladas a $-70{ }^{\circ} \mathrm{C}$, e assim permaneceram por 48 horas, quando foram descongeladas e submetidas à contagem de células viáveis através de coloração com corante azul de tripan em câmara de Fuchs-Rosenthal. Como controle foi utilizada contagem de células sem congelamento ou adição de DMSO. As contagens foram feitas em quadruplicata. As análises estatísticas foram realizadas pelo software BioEstat versão $5.3^{\circledR}$ e constaram de análise de variância com comparação entre médias pelo teste de Tukey, adotando significância de $95 \%(p<0,05)$.

\section{RESULTADOS E DISCUSSÃO}

Após a análise dos dados, a Figura 1 foi gerada e indica os percentuais de inibição do crescimento celular em função do tempo de exposição ao DMSO. Os resultados demonstram que não houve diferença estatística entre os tratamentos 0,5\%, 1\% e 2,5\%, exceto após 24 horas de exposição $(p<0,05)$ e, também, estes tratamentos apresentaram melhores viabilidades celulares, quando comparados ao controle (0\% DMSO). A inibição do crescimento celular não ultrapassou $22,84 \% \pm 3,97 \%$ nesses tratamentos. Já o tratamento com $5 \%$ de DMSO diferiu de todos os demais $(p<0,05)$ apresentando $20,26 \% \pm 2,64 \%$ de inibição em apenas 1 hora de incubação e, ao final das 24 horas 43,05\% $\pm 4,68 \%$. Isso demonstra que 2,5\% de DMSO é a máxima concentração que não causa prejuízos para o crescimento celular. As maiores concentrações (10\% e $20 \%$ ) diferiram de $5 \%$ de DMSO, porém não diferiram entre si ( $p>0,05)$, apresentando $55,23 \% \pm 5,12 \%$ e $62,87 \% \pm 3,97 \%$ de inibição celular, respectivamente. 


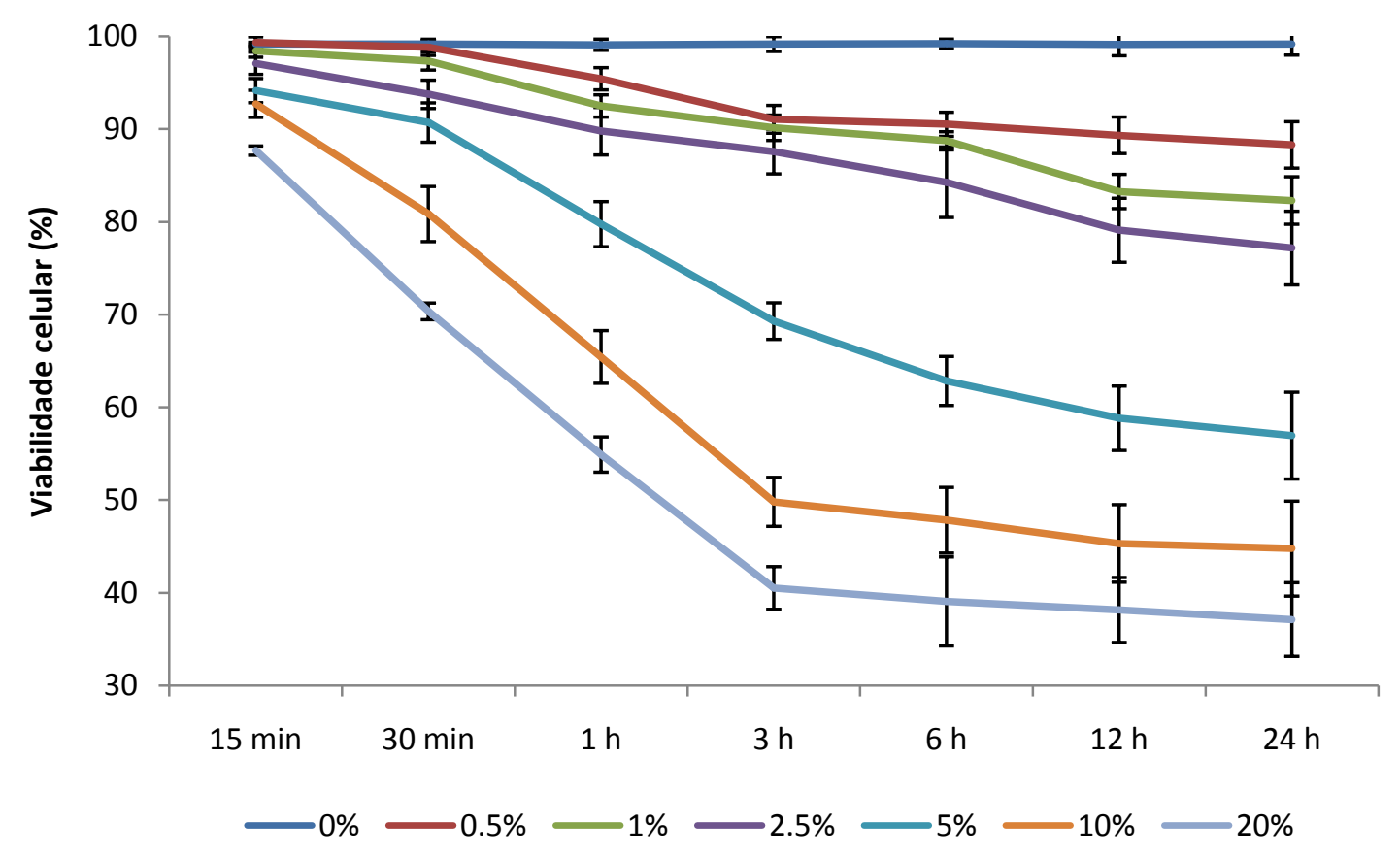

Figura 1 - Percentual de viabilidade celular em função do tempo de exposição a diferentes concentrações de dimetilsulfóxido (DMSO) avaliado pelo método MTT.

As células MDBK se mostraram sensíveis ao DMSO, sendo que 5\% de DMSO causou morte ou inibição do crescimento celular, o que vai de encontro a muitos dados encontrados na literatura afirmando sobre a baixa toxicidade do DMSO (ALVES, 1998; BRAYTON, 1986; STURION et al., 1999). Esses dados foram obtidos a partir de estudos in vivo, nos quais a dose letal 50\% foi bem elevada, demonstrando baixa toxicidade (STONE, 1993). Kunert Filho et al. (2008) encontraram, em ensaio de redução do MTT, 12,5\% de DMSO como a melhor viabilidade celular após o descongelamento, demonstrando a eficácia do DMSO como crioprotetor nessa concentração.

O congelamento de células exige um crioprotetor e o DMSO atua satisfatoriamente como tal, sendo um dos crioprotetores celulares mais utilizados (MASSUMOTO et al., 1997). Em nossos experimentos com relação à viabilidade celular após descongelamento, a Figura 2 ilustra as contagens de células viáveis pelo método da coloração com azul de tripan. 


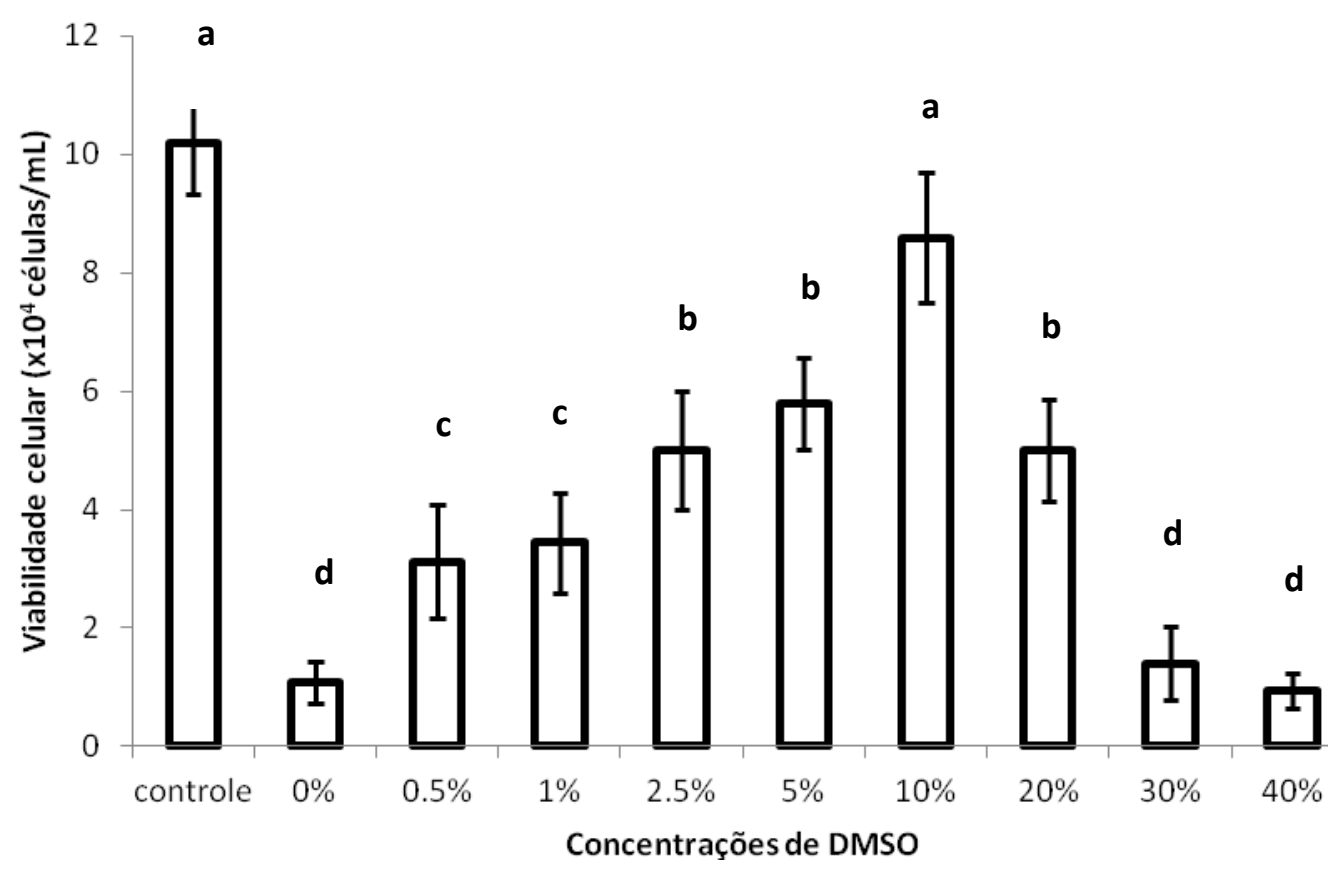

Letras diferentes indicam diferença estatística $(p<0,05)$.

Figura 2 - Contagem de células viáveis após descongelamento de células que foram congeladas com diferentes concentrações de dimetilsulfóxido (DMSO). O controle de células não sofreu congelamento ou adição de DMSO.

O congelamento sem a utilização de DMSO (0\%) (Figura 2) apresentou apenas 1,09 \pm 0,35 $x$ $10^{4}$ células viáveis/mL (10,7\% em relação ao controle), demonstrando a necessidade da utilização de um crioprotetor no congelamento celular. Concentrações de 0,5\%, 1\% e 2,5\% de DMSO, embora tenham apresentado as maiores taxas de viabilidade celular quando testadas sobre células MDBK por até 24 horas, não foram suficientes para impedir o rompimento celular pelo congelamento e descongelamento, apresentando índices de 30,6\%, $33,6 \%$ e $49 \%$ de células viáveis em relação ao controle, respectivamente.

Observamos que o protocolo utilizando 10\% DMSO teve maior média de viabilidade celular após descongelamento $\left(8,6 \times 10^{4}\right.$ células $/ \mathrm{mL}, 84,3 \%$ com relação ao controle) não diferindo do controle $(p>0,05)$. De acordo com a literatura, o DMSO em altas concentrações (acima de 20\%) torna-se tóxico para as células e por esse motivo, preconiza-se a utilização, para congelamento celular, em concentrações de $5 \%, 10 \%$ e $20 \%$, sendo que esta última é pouco utilizada. (MASSUMOTO; MIZUKAMI, 2000). Em nosso estudo, a maior concentração de DMSO apta para uso, com baixa toxicidade celular, foi de 2,5\% para as células MDBK (Figura 1), demonstrando a toxicidade que este composto exerce sobre as células, sugerindo que deva ser utilizado apenas momentos antes do congelamento. 
Galmes et al. (2007) relatam que células tronco hematopoiéticas criopreservadas com DMSO a 5\% apresentaram, após descongelamento, regeneração mais lenta quando comparadas ao grupo criopreservado com DMSO a 10\%, sugerindo que a maior concentração aumenta a proteção ou conservação das células. A queda na viabilidade celular pode ser resultante de danos celulares causados durante a criopreservação pela formação de cristais de gelo e no descongelamento. Esses dados corroboram com nosso estudo, que também demonstrou que a maior taxa de recuperação celular após o descongelamento foi quando se utilizou DMSO a $10 \%$ como crioprotetor.

As concentrações mais elevadas testadas também apresentaram baixa contagem de células viáveis após o descongelamento, provavelmente pelo poder tóxico do DMSO, motivo esse que ressalta a importância da colocação da concentração adequada de DMSO apenas no momento do congelamento, assim como a necessidade da retirada do DMSO assim que as células forem descongeladas. Isso se consegue através de centrifugação, aspiração do sobrenadante e ressuspensão das células em novo meio de cultura.

\section{CONCLUSÃO}

Através dos dados obtidos, conclui-se que o DMSO é útil nos protocolos de congelamento celular na concentração de $10 \%$, porém com a precaução de adicioná-lo sobre as células apenas no momento do congelamento, com retirada logo após o descongelamento, devido à toxicidade que essa concentração (10\%) exerce sobre as células MDBK.

\section{TOXICITY AND EFFICIENCY OF DIMETHYL SULFOXIDE (DMSO) ON THE FREEZING OF MADIN-DARBY BOVINE KIDNEY CELLS (MDBK)}

\section{ABSTRACT}

D imethyl sulfoxide (DMSO) is a compound used worldwide as an organic solvent and in the last decades is being applied in medicine as anti-inflammatory. In cell culture laboratories it is used as cellular cryoprotectant and so we aimed to study the toxicity and efficiency of DMSO in cell freezing in different concentrations and cell exposure times. MDBK (Madin-Darby Bovine Kidney) cells were cultured in 96 well plates and after DMSO, was added to the wells, in concentrations between $0,5 \%$ and $20 \%$, and the cell viability was 
measured by the MTT test in periods ranging from 15 minutes to 24 hours of exposure. MDBK cells cultured in bottles were trypsinized and frozen with different concentrations of DMSO and, after thawing the viable cell count was performed with trypan blue. The results obtained showed that there was not difference $(p>0,05)$ among the treatments with $0,5 \%$, $1 \%$ and $2,5 \%$ of DMSO, once the cell death did not exceed $22,84 \% \pm 3,97 \%$ with 24 hours of incubation, but in higher concentrations, with only 1 hour, the cell death rate has exceeded $20 \%$, differing from the control $(p<0,01)$. After thawing, the best protocol was that which used $10 \%$ of DMSO, and did not differ from the control $(p>0,05)$. Non-toxic concentrations for the cells evaluated by MTT $(0,5 \%, 1 \%$ and $2,5 \%)$ were not able to prevent cell rupture after freezing and thawing. We conclude that the use of cryoprotectants for freezing is necessary, but the DMSO addition should be just moments before freezing due to its toxicity when incubated with the cells.

Keywords: Cryopreservation. Cell culture. Cytoprotective.

\section{LA TOXICIDAD Y LA EFICACIA DE DIMETILSULFÓXIDO (DMSO) SOBRE LA CONGELACIÓN DE CÉLULAS MADIN-DARBY BOVINE KIDNEY (MDBK)}

\section{RESUMEN}

$\mathrm{D}$ imetilsulfóxido (DMSO) es un compuesto mundialmente utilizado como un disolvente orgánico que en las últimas décadas se ha aplicado principalmente en la medicina como un anti-inflamatorio. En los laboratorios de cultivo celular se utiliza rutinariamente como crioprotector de células y por lo tanto nuestro objetivo fue estudiar la toxicidad y la eficacia del DMSO en la congelación de células, en diferentes concentraciones y tiempos de exposición. Las células MDBK (Madin-Darby Bovine Kidney) fueran cultivadas en placas de 96 pocillos y posteriormente DMSO en concentraciones que van del $0,5 \%$ al $20 \%$ se añadió a períodos que van desde 15 minutos a 24 horas de exposición. A partir de entonces, la viabilidad celular se evaluó mediante el ensayo de 3- (4,5-dimetiltiazol-2-il) -2,5 bromo difenil-2H-tetrazolato (MTT). Al mismo tiempo, células MDBK cultivadas en botellas fueron tratadas con tripsina y congeladas con diferentes concentraciones de DMSO. Después de la descongelación se realizó recuento de células viables con azul de tripano. Los resultados no mostraron diferencias $(p>0,05)$ entre los tratamientos utilizando $0,5 \%, 1 \%$ y $2,5 \%$ de DMSO una vez que la muerte celular no excedió $22,84 \% \pm 3,97 \%$ en 24 horas de incubación. Sin embargo, los tratamientos con concentraciones más altas, con sólo una hora de incubación, la tasa de muerte celular excedieron $20 \%$, a diferencia del control $(p<0,01)$. Después de la descongelación, el mejor protocolo fue aquél con DMSO al 10\%, no difiriendo de control $(p>0,05)$. Concentraciones no tóxicas para las células evaluadas por el ensayo de MTT no fueron capaces de evitar la ruptura celular después de la congelación y descongelación. En conclusión es necesario el uso de crioprotectores para la congelación, 
pero la adición de DMSO debe ser sólo momentos antes de la congelación debido a su toxicidad cuando se incubaron con células.

Palabras clave: Crioconservación. Cultivo celular. Citoprotector.

\section{REFERÊNCIAS}

ALSUP, E. M.; DE BOWES, R. M. Dimethylsulfoxide. Journal of the American Veterinary Medical Association, v. 185, n. 09, p. 1011-1014, 1984.

ALVES, G. E. S. Dimetilsulfóxido (DMSO): Considerações gerais sobre as particularidades e versatilidade. Saúde Equina, v. 6, p. 6-10, 1998.

BANNISTER, J. V.; BANNISTER, W. H.; ROTILS, G. Aspects of the structure, function and applications of superoxide dismutase. CRC Critical Reviews in Biochemistry, v. 22, n. 2, p. 111-180, 1987.

BRAYTON, C. F. Dimethylsulfoxide (DMSO): a review. Cornell Veterinarian, v. 76, n. 1, p. 7690, 1986.

CARPENTER, R. J.; ANGEL, M. F.; MORGAN, R. F. Dimethyl sulfoxide increases the survival of primarily ischemic island skin flaps. Otolaryngology Head Neck Surgery, v. 110, p. 228-231, 1994.

DE VRIES, E. G.; VELLENGA, E.; LUIN-NELEMANS, J. C. The happy destiny of frozen haematopoietic stem cell: from immature stem cells to mature applications. European journal of cancer care, v. 40, p. 1987-1992, 2004.

GALMES, A.; GUTIÉRREZ, A.; SAMPOL, A.; et al. Long-term hematologic reconstituition and clinical evaluation of autologus peripheral blood stem cell transplantation after cryopreservation of cells with $5 \%$ and $10 \%$ dimethilsulfoxide at $-80{ }^{\circ} \mathrm{C}$ in a mechanical freezer. The Hematology Journal, v. 92, n. 7, p. 986-989, 2007.

KUNERT FILHO, H. C.; HOLZ, C. L.; DEZEN, D.; et al. Determinação da taxa de recuperação e viabilidade de células MDBK após congelamento com dimetilsulfóxido (DMSO) ou glicerol. In: CONGRESSO BRASILEIRO DE MEDICINA VETERINÁRIA, 35, 2008, Gramado. Anais. Gramado: SBMV, 2008.

MASSUMOTO, C. M.; MIZUKAMI, S.; CAMPOS, M. F.; et al. Criopreservação de medula óssea e células pluripotentes periféricas utilizando um congelador programável: experiência em 86 congelamentos. Revista da Associação Médica Brasileira, v. 43, n. 2, p. 93-98, 1997. 
MASSUMOTO, C. M.; MIZUKAMI, S. Transplante autólogo de medula óssea e imunoterapia pós-transplante. Medicina, Ribeirão Preto, v. 33, p. 405-414, 2000.

MOSMANN, T. Rapid colorimetric assay for cellular growth and survival: application to proliferation and cytotoxicity assays. Journal of Immunological Methods, v. 65, n. 1-2, p. 5563, 1983.

ROSENBAUM, E. E.; HERSCHLER, R. J.; JACOB, S. W. Dimethyl sulfoxide in musculoskeletal disorders. Journal of the American Medical Association, v. 192, n. 02, p. 309-313, 1965.

RUBIN, L. R. Toxicologic update of dimethyl sulfoxide. Annals of the New York Academy of Sciences, v. 411, p. 06-10, 1983.

SHIRLEY, S. W.; STEWART, B. H.; MIRELMAN, S. Dimethyl sulfoxide in treatment of inflammatory genitourinary disorders. Urology, v. 11, n. 3, p. 215-220, 1978.

STONE, R. W. Clinical updates on the use of dimethyl sulfoxide. Canine Practice, v. 18, p. 1619, 1993.

STURION, D. J.; PINHEIRO, E. R.; PARDO, P. E.; TANAKA, N. M. Efeitos hepatotóxicos e nefrotóxicos do dimetilsulfóxido em aplicações tópicas em cães. Revista Unopar Científica Ciências Biológicas e da Saúde, v. 1, p. 41-47, 1999.

TONER, M. Nucleation of ice crystals inside biological cells. In: STEPONKUS, P. Lowtemperature biology. London: JAI Press, 1993, p. 1-51.

Autor para correspondência: Tony Picoli.

Universidade Federal de Pelotas, Faculdade de Veterinária - Campus Universitário Capão do Leão. CEP - 96010 900 - caixa postal 354, Capão do Leão (RS), Brasil. picolivet@gmail.com 